\title{
Challenges of Minority Teachers in a Western Society: Experience in Austria
}

\author{
Nasy Inthisone Pfanner \\ B.O.RG Dornbirn-Schoren
}

\begin{abstract}
Correspondence concerning this article should be addressed to Nasy Inthisone Pfanner, secondary school B.O.RG Dornbirn-Schoren, Höchsterstraße 32, Dornbirn, Austria, 6850. E-mail: nasypfanner@gmail.com
\end{abstract}

\begin{abstract}
The aim of this reflective article is to investigate firstly, the preconception of professionalism in teaching; secondly, whether minority teacher's identity influences their professionalism; and, thirdly, how minority teachers affect minority students, since minority teachers face real inequality in white societies. The issue of teacher professionalism has always been controversial due to the changing nature of the profession and society's expectations of how the profession should be. There has not been an investigation regarding minority teachers in Austria. I wish to address this gap in the research by investigating the experience of a Laotian-American in a secondary school. The investigation reveals that in spite of the efforts that governments in Canada, the United States, New Zealand, and the United Kingdom have put into recruiting minority educators, minority teacher population does not keep pace with the minority student populations. Regrettably, Austrian government does not have such a recruiting scheme. This study has the potential to raise debates about minorities in the Austrian educational system and contribute to existing discussion about minority educators in white society.
\end{abstract}

Keywords: Asian minorities, professionalism, English as a Second Language teachers, reflective teacher, diversity in education

The aim of this reflective article is to investigate firstly, the preconception of professionalism in teaching; secondly, whether minority teacher's identity influences their professionalism; and, thirdly, how minority teachers affect minority students, since minority teachers face real inequality in white societies. The issue of teacher professionalism has always been controversial due to the changing nature of the profession and society's expectations of how the profession should be (e.g. see Kennedy, 2007 for a discussion). The gap in research can only be filled when more investigation is conducted internationally. There has not been an investigation regarding minority teachers in Austria. I wish to address this gap in the research by investigating the experience of a LaotianAmerican in an Austrain secondary school. This study has the potential to raise debates about minorities in the Austrian educational system and contribute to existing discussion about minority educators in white society.

The author draws her recent experience of working in the Bundesrealgymnasium Dornbirn-Schoren (BORG Dornbirn-Schoren), a Gymnasium or grammar schools with over 800 pupils and almost one hundred teachers in Vorarlberg. The purpose of the school is to prepare pupils for university study. Being a LaotianAmerican woman, the author encountered challenges from the first day that she entered the classroom. Despite her Master's degrees in Education and in the German language and literature, many questioned whether she understood the Austrian school system and whether her German was good enough. Having been hired she had the backing of the Headmaster and the Department of Education; she still felt undervalued. The author focuses on the challenges of Asian teachers of English in a western society and shares her experience of teaching at a state secondary school in Austria.

\section{Materials and Methods}

\section{Definition of Professionalism}

Professionalism is when a person conforms to the technical and/or ethical standards of his/her profession 
(Nicholson, 2014). According to Whitty (2008), western sociologists began listing features that occupations should have to qualify as a profession in the 1950s. Millerson (1964, cited in Power, 2008) posits that a profession ought to have the following characteristics: 1) skill based on theoretical knowledge, 2) trust base client relationship, 3) adherence to a professional code of conduct, 4) independence, and 5) altruism. These characteristics were associated with the classical professions such as law, medicine and theology. Hart and Marshall (1992) question the notion of professionalism because it divides society into classes. For example, the classical professions possess high quality of professionalism whereas manual professions display lesser qualities. The correlation between the level of the profession and salary is evident.

Some researchers challenge the traditional understanding of professionalism. As Hargreaves (2000, p. 152) posits, "The concepts of professionalism and professionalization are 'essentially contested'....”. Likewise, Siegrist (1994, cited in Power, 2008) and Hanlon (1998, cited in Whitty, 2008) claim the meaning of professionalism to be constantly changing depending on time and place. Brindley (2015, pp. 24-25) echoes the same opinion in her thesis "... professionalism is open to re-interpretation...”. In the same vein, Power (2008) implies that traditional perception of professionalism is outdated and concurs that the quintessential image is a far cry from the daily practice of professionals. There is no longer a list with clear definitions, but rather expectations overlap. Barnett (2008, p. 191) rightly claims that “... the old narratives of the professional life weaken...". These arguments suggest that the meaning of professionalism is not static. The advantage is that no one is confined to meanings that were created before present time. The drawback is that without a clear definition people lack guiding principles.

New professions can be created anytime. The reasons for this change are the increase of life expectancy combined with the smaller family, and the invention of technology. Basing on past results, it is possible to predict that in the future, as the family structure continues to evolve and technology continues to develop, many more professions will be created. Greenwood (1957, cited in Hart \& Marshall, 1992) seems to be right when he proposes looking at professionalism as a continuum which encourages a broader look at not just the profession, but the situation in which the profession exists.

To summarize, there is no absolute meaning of professionalism, but there is extensive literature that describes and defines it. After carefully scrutinizing the literature, the author takes a middle-ground position and would argue that there should be a list of features and characteristics to follow, but it should be flexible enough to meet the rapidly changing world.

\section{Teacher Professionalism}

'...it is certainly a struggle among different stakeholders over the definition of teacher professionalism and professionality for the twentyfirst century .... (Whitty et al., 1998, p. 65) Hargreaves (2000) examines the four historical phases of professionalism that are frequent to Anglophone cultures, which is a focus of this article. The phases will be used as a base for the author's discussion because the various ages cover all aspects of professionalism from the very simple up to the modern time.

Pre-professional age, the first phase, was technically simple, without formal training, teachers learned through trial and errors, limited financial support from the government. The second phase, Age of the autonomous professional, starting from the 1960s teachers enjoyed higher status and pay, remarkable autonomy, individualism, were connected to higher learning institutions, and received generous financial support from the government. In the third phase, Age of the collegial professional, as schools became more complex in the 1980s, teacher individualism became unsustainable, which moved teaching towards a collegiate approach, and professional training occurred on-site. The fourth age, post-professional or postmodern, an age with major development in economics and communications at the turn of the millennium, attack on professionalism in education which leads to financial cutbacks, endless information is being circulated everyday leading to continual debates about what and how to teach, resulting in de-professionalization. While Hargreaves (2000) provides a framework to understand the development of professionalism, it is vital to consider that teaching does not fit neatly into any phase. For instance, given that teachers in Austria have on-site professional development trainings and are undergoing financial cutbacks, it is obvious that the profession is stretched between the age of the collegial professional and the fourth age-post-professional or postmodern.

Hart and Marshall (1992) list five essential features of teacher professionalism: 1) specific body of knowledge, 2) ideal of service, 3) ethical codes, 4) autonomy, and 5) distinctive culture. At the same time, Hart and Marshall (1992) refer to Ginseng's (1988) point that such a list has restrictions. Without a doubt, the features can be applied to all teaching, but it is vital to acknowledge that teaching still differs greatly, according to time and context.

Macklin (1981) contends that autonomy is the key to professionalism and the professional owning technical knowledge and a culturally respected social ideal. Basing on the claim by Macklin (1981), it is arguable that teaching in Austria is a highlevel profession. Teachers enjoy a large amount of autonomy. Every state has a Department of Education 
with an inspector for each subject, who sits at a teacher's lesson and evaluates the teaching. Since there is only one inspector per subject, it is impossible to get to everyone. This leaves the quality of education up to the headteachers. This is not simple because headteachers do not hire teachers, but rather teachers are employed by the Department of Education, which interviews, hires and dismisses teachers. So, unlimited autonomy could be problematic, as some teachers might take advantage of the system and do as little as possible.

Hart and Marshall (1992) conclude that the overall teaching profession is questionable to society. They point to the trend that many states hire people with little or no professional knowledge, the increase of home schooling and private schools. Hart and Marshall (1992) fail to consider the following reasons as to why some parents send their children to private schools: 1) religious affiliation; they want their children to grow up with people of the same beliefs, values, and principles, 2) safety; especially in the United States schools are targets of shooting, and 3) status; the wealthy want their children to meet and marry within the same social class. There is an alarming culture of distrust that puts teachers in a contradicting discourse and damages the public trust.

Similarly, teachers in Austria no longer enjoy high esteem. To illustrate, there are many cases in Vorarlberg where the situations in mathematics and physics are so dire that schools have hired foreigners with certificates from their home countries, but who speak limited German. As a result, there is much misunderstanding. Again, similarly, some schools have cancelled certain subjects altogether due to teacher shortage. Understandably, the frustrated parents complain and blame schools for not providing adequate education. Secondary school teaching in Vorarlberg still has all the features as suggested by Hart and Marshall (1992) and requires formal training as set forth by the Ministry of Education. But, it is also undergoing serious public assault to a degree where trust can hardly be restored. Finally, on the basis of personal reflections, professional experience and literary research, it seems possible to conclude that teacher professionalism is a socially changing theory, the existence and value of which are both supported and questioned by society.

\section{Results and Discussion}

\section{Assumption of "Whiteness" with English Language Teaching de-Professionalizes the Profession}

'White privilege is like an invisible weightless knapsack of special provisions, maps, passports, codebooks, visas, clothes, tools and blank checks. (McIntosh, 2015, p. 241) In the field of English language teaching, "whiteness" is assumed to be associated with authentic English. To demonstrate, Amin (1997), a Pakistani ESL educator who relocated to Canada as an adult has taught ESL to adults in Toronto, claims that her student did not consider her native nor Canadian. In her 1994 research with five minority ESL teachers in Toronto, she discovered that her participants believed ESL students considered only white people to be native speakers of English. Armin (2001) interviews eight minority immigrant women teachers who taught ESL classes to adult immigrants in Toronto. Some of her subjects' students were so disappointed for not having a white teacher that they quit the classes. The similarity between Tang's (1997) survey of non-native speaking teachers in a teacher retraining course in Hong Kong and Clark and Paran's (2007) study of the marketability of non-native speakers in the United Kingdom is that they concur native speakers have a higher status than non-native speakers in the English language teaching industry.

Being a Laotian-American, who was rejected at first as a professional by a "white" community, the author had hoped to learn from other Asian minorities with similar life experience. Here the term "Asian" people refers to people from the Far East, Southeast Asia, and the Indian subcontinent. Society's association of teacher with "whiteness", instead of focusing on the quality of training, ethical standards, and relationship, automatically causes minorities to be looked at with suspicion.

\section{Cross-National Comparison}

Developments in Canada, the United States, New Zealand, and the United Kingdom are of high importance for this research because they have a large Asian population. Austria has a small Asian population, but concerns the author since it is the place where she practises her profession. So, the purpose of this article is also to investigate how the various minority teachers' professionalism compares in different contexts.

Canada: Researchers Majhanovich and RezaiRashti (2002) studied six retired minority women teachers' experiences starting from the 1960s in Ontario. The researchers claim that racism stopped the women from achieving career advancements. Even though the study offers some rational explanation as to the teachers' lack of progress, it is not as simple as it seems. Firstly, what appeared to be discrimination on the surface might well be argued as a case of bureaucracy. As Cruickshank (2004) notices in his study of 110 immigrant teachers in Australian education programs, one of the difficulties was gaining accurate 
information pertaining to qualification recognitions. Likewise, Mawhinney and $\mathrm{Xu}$ (1997) claim that foreign trained teachers come to Ontario with great expectations only to realize that their credentials are not recognized. Secondly, the teachers observed were two Jamaicans, two Pakistanis, one Taiwanese and one Egyptian. Canadian universities have a very high academic standard. Thus, it is questionable whether the quality of education provided by the teachers from Jamaica, Pakistan and Egypt is on par with the Canadian system. Although Taiwan's students even ranked higher on the Programme for International Student Assessment (PISA), which compares test results of 15 year-olds worldwide. From the test results of 2012 Canada's student placed $9^{\text {th }}$ in reading and $13^{\text {th }}$ in mathematics, Taiwan's students placed $8^{\text {th }}$ and $4^{\text {th }}$, respectively (BBC News, 2015). And, Canada's education system was ranked $5^{\text {th }}$ best in the world in 2015 (MBC Times, 2015). In contrast, neither Jamaica, Pakistan, nor Egypt made it on the list.

Mawhinney and Xu (1997) analyze the Faculty of Education at the University of Ottawa's program to help foreign trained teachers get credentials. In 1994, they observed seven teachers who successfully finished the program with high hope. Notwithstanding, the teachers experienced discrimination based on their accents.

The United States: The lack of research on minority teachers motivated Subedi (2008) to study the experiences of two South Asian female teachers in an urban large mid-western city. The author observes that Nadia, a Pakistani teacher, whose identity, linguistic style came across as less qualified. Students did not accept her as a 'real' teacher. In contrast, Anita, an Indian teacher was received with higher esteem (Subedi, 2008). The reason behind this is easy to understand: in the United States, Asians are the model minority, people who achieve higher success than the average population academically as well as economically, and there are many prominent Indians in America. Although Nadia and Anita are both minorities, they have different nationalities.

New Zealand: The lack of research concerning under-representation of ethnic minorities teachers encouraged Howard (2009) to interview 15 South Korean and Chinese students aged between 16 and 18 in their last two years of secondary schools and their parents, to determine why they do not enter the teaching profession. Unlike the above stated studies, here the researcher was trying to find what information and/or social expectations discouraged the students from becoming a teacher. Generally, South Korean and Chinese students are highly academic. Some notable examples are that the Chinese are placed first and South Koreans - fifth in the PISA 2012 exam in both reading and mathematics (BBC News, 2015). Howard (2009) discovered 17 reasons that discourage the students from choosing the teaching professions. These top the list: 1) low salary, 2) low status, 3) negative public image, 4) low student respect, 5) poor student behavior, 6) responsible for student outcome, 7) absence of role models, 8) racism, 6) language difficulty, 7) parental expectations, 8) lack of intellectual challenge, and 9) lack of advancement opportunity.

The United Kingdom: A study by Wilkins and Lall (2011, cited in Eweka, 2015) found 30\% of minorities, in comparison to $10 \%$ white failed or quit their teacher training programme from 2002 to 2006. Likewise, Carrington et al. (2001) identified that minority student teachers were much older and were from non-traditional academic backgrounds. Carrington et al. (2001), cited in Eweka (2015), observe that a large number of graduates turned down teaching due to low prestige. Eweka's (2015) study into school leadership aspirations of black and ethnic minority teachers' claims that there are many reasons for low representation ranging from discrimination to policy failure at various levels from beginning to top. Butt et al. (2010) studied 12 British South Asian women to investigate whether their ethnic minority status influenced their teaching profession and whether it had influenced their quality of training. The longitudinal study began at the culmination of their Initial Teacher Training (ITT) till the end of their third year of teaching, altogether four years. They found that overall the participants considered teaching to be a respectable profession in their environment for women and that it "fitted" well in family planning, but was not high enough status for men who preferred to go into higher status profession such as law, medicine, etc.

Austria: No research has focused on Asian minority students or teachers, but still some studies concerning other ethnic minorities in Austrian schools can be found. The research findings are possibly similar to other studies regarding minorities. According to Luciaka and Khan-Svik (2008), the majority of these students are Austrian-born children of migrants and offsprings of the so-called 'guest workers,' the children of refugees who came to the country in the wake of the Yugoslavian civil war in the 1990s. Luciaka and Khan-Svik (Luciaka \& Khan-Svik, 2008) observe that teachers in Austrian schools are mostly monolingual and mono-ethnic. Until recently, only a few individuals with an immigrant background study at teacher training institutions; those who did encountered many hurdles. For example, Sertl (2004), cited in Luciaka and Khan-Svik (2008), notes that one student was scolded for speaking Turkish when she and a Turkish peer were unable to follow certain instructions in class.

In brief, the literature suggests that minorities come from challenging backgrounds as compared to 
their white counterparts. Furthermore, appearance and accents are blocking minorities from being accepted as professionals. It is vital to consider that a low salary and limited opportunity for advancement do not only deter minorities from going into teaching, but also the general public. A key thing is not to generalize, but rather to study each case separately. For instance, in countries where teachers enjoy a high pay and status such as Finland, Switzerland and Singapore, there is no teacher shortage.

\section{Schools Do not Reflect Society's Demographic}

'In many Western countries, there is a shortage of minority teachers. Although an increasing number of students are members of minority groups, teaching staff tend to come from the majority group. This disparity in the cultural backgrounds of teachers and those of the children they teach often results in low teacher expectations and the use of inappropriate teaching strategies. Recruiting quality minority teachers, therefore, is very important' (Cooper \& Alvarado, 2006, pp. 5-6).

Research in Canada, the United States, New Zealand, the United Kingdom, and Austria shows that the teacher population does not reflect the multiethnic student population. It is doubtful that teachers who are different from their students can understand where the students are coming from. With a diverse group of people, fear and misunderstanding can easily occur. Fortunately, the governments in Canada, the United States, New Zealand, and the United Kingdom recognize the problem and are responding to the crisis.

Canada: Antonelli et al. (2009) point to university programmes that have been set up to help minorities become teachers across the country and through a government program called Teach in Ontario. Coutts (2013) also shows a Toronto board memo that was sent to principals and teachers that stated both men and minority are preferred in the hiring process to fulfill their goal of equal representation in both gender and cultural diversity. In defiance of established policies to promote equality, women and visible minorities are still underrepresented, earn less and suffer higher unemployment rate in Canadian higher education (CAUT Education Review 2010).

The United States: Egalite and Kisida's (2015) article claims that in 2014, ethnic minorities made up a majority of America's public school students for the first time and that the trend will continue to rise. Richard and May (2011) view this teacher-student disparity as a civil rights issue, suggesting that a minority teacher shortage leads to a minority student failure. The National Education Association (2015) has made effort to recruit minority teachers by formulating such resolution:
'The Association urges local and state affiliates and appropriate governing bodies and agencies to work to increase the number of ethnic-minority teachers and administrators to a percentage at least equal to, but not limited to, the percentage of the ethnic minorities in the general population.

New Zealand: Howard (2009) acknowledges that the highest level of government is trying to attract minority students through recruitment campaigns and scholarships.

The United Kingdom: The government's fear that teaching was a white-middle class profession was so great that they spent a lot of money and effort to recruit and retain ethnic minorities into the teacher profession (DfEE, cited in Butt et al. (2010). But the trainees did not want special treatment and some believed that the universities were trying to fulfill a quota, thus felt that they were only accepted based on their minority status (Butt et al., 2010).

Austria: Unlike the countries discussed above, Luciaka and Khan-Svik (2008) postulate that educational performance amongst ethnic groups is hardly ever discussed, nor has it been a subject of research. Basing on the lack of interest and personal observation, it is possible to hypothesize that the situation will not improve. On the contrary, the situation is alarming given that foreigners make up almost $10 \%$ of the population. The largest Asian minority groups comprised of Filipinos 30,000, Pakistanis 4,000 and 1,250 Nepali (Wikipedia, 2015).

To summarize, the literature suggests that the teaching population needs to reflect the general population's ethnicity. While the government's effort to level the playing field is commendable, it is important to be careful not to put race above merit. It would be wrong to accept or reject anyone into any program basing simply on skin color.

\section{Minority Teachers' Positive Effects}

'In our efforts as teacher educators, we can benefit from the ways in which immigrant teachers challenge our own taken-for-granted assumptions about teaching young children. We may believe that we are constructivist teachers (or any other type of teacher), but listening to diverse groups of practicing teachers can reveal when we ourselves fall short of our stated pedagogical principles' (Adair, 2011, p. 68). The central belief from Adair (Adair, 2011, p. 68) and Rebecca Klein's (2015) article in The Huffington Post is that the presence of minority teachers will affect minority students positively. Additionally, Howard (2010) refers to an international research which suggests that not only minority students, but all students profit from a diverse teacher population. Being the only Asian teacher at a particular secondary school in Vorarlberg, 
the author has been able to educate students concerning Asian people and culture in a way that no other teacher can do.

Opponents such as Egalite and Kisida (2015) caution that there are hardly any rigorous empirical studies to back the claims that the presence of minority teachers will benefit minority students. By criticizing the lack of evidence, Egalite and Kisida are highlighting the need for more research.

Likewise, Hurtado (2001) alerts that measuring the effects of diversity is difficult because it is not easily visible. Furthermore, Villegas and Davis (2007), cited in Antonelli et al. (2009), assert that race alone does not equal a better learning experience. Equally important, Antonelli et al. (2009) claim that not all minority teachers are role models and that many white educators have much to offer minority students. To speculate about the quality of education based on skin color alone would be dangerous.

In summary, there is insufficient research on how minority teachers affect minority students to draw any firm conclusions. Above all, being a minority student as well as teacher, the author is concerned about the status quo. The researchers have made her more aware of her own academic challenges and success. Specifically, when she grew up in northern Utah or even when she was a student in Germany, she did not experience one minority educator. However, when she was a master's level student at the University of Michigan, there were many minority professors and administrators. The author succeeded in her studies with and without minority educators, but nonetheless, it was very encouraging to have minority professors and administrators.

\section{Lessons Learned}

'An important point here is that it not only concerns one's actions, intentions and experiences, but it also permits the viewing of one's representations as representations, one's beliefs as beliefs' (Von Wright, 1992, p. 61). The concept of professionalism helps to look deeper into personal teaching at a secondary state school. Personal experience proves that teaching is a traditional profession and particularly in an institution which is funded by public money will have the characteristics as listed by Millerson (1964), cited in Power (2008). As a lone Laotian-American professional in a homogeneous society, the author had to get people to look beyond her race. Although she was unable to find any research regarding Laotians in the teaching profession nor statistics about Laotians in Austria, the literature and her own experience confirm that Asian women face obstacles. Experience shows that there is no point in arguing with people, but rather to respond by doing good work, that speaks for itself. Today, in her fifth year of teaching, the teacher population is still white, but the author no longer feels any barrier separating her from parents, students or colleagues. This experience has taught her that skin colour matters in the beginning, but with sincere effort from everyone, bias can be buried.

\section{Conclusion}

The aim of this reflective article was to investigate the preconception of professionalism in teaching, whether minority teachers' identity influences their professionalism, and how minority teachers affect minority students. There is abundance of research concerning "professionalism" and "teaching" that debate the meaning of professionalism and the validity of the teaching profession. The analysis of the literature showed that the debate is open-ended. It is difficult to pinpoint oneself in any one phase of professionalism as suggested by Hargreaves (2000) because the author believes that the nature of the teaching profession is fluid. However, the features suggested by Hart and Marshall (1992) helped the author to reflect on how and why she became a teacher, and question whether she would want to continue in the chosen profession.

Research suggests that the teacher population does not reflect the changing faces of multi-ethnic classrooms, which are in need of role models. While the governments in Canada, the United States, New Zealand, the United Kingdom are implementing programs to recruit more minority teachers, so far, Austria has no such recruitment scheme. Without a doubt, Austria must reconsider its policy given the number of recent refugee children who are already burdening the school system.

This reflective process has made the author aware of how under-represented minority teachers are in the teaching profession and that basing on their cultural background and appearance alone, they are scrutinized by many societies that associate teaching and learning with "whiteness." In particular, this statement is based on the opportunity to reflect on the author's own identity in a "white" society. Her experience as a Laotian-American in Austria is similar to other teachers that she has discovered, namely, she had to prove herself before she was recognised as a professional; polite, meticulous, diligent, and comply to the ethical expectations (Nicholson, 2014). She had a chance to reflect on her own professionalism in comparison to other teaching professionals in various cultures and in a different time frame. The stability of any society depends on its members' ability to live and work together peacefully. The key to success begins 
with our educational system which needs to serve all members of society, both the marginalized and the privileged. It is difficult to help minority teachers and students succeed without a full assessment of the situation. This reflective article contributed to the much needed discussion on teaching professionalism for minorities; however, much more needs to be explored. Meanwhile, Bush et al. (2007, 2005) studies cited in Eweka (2015) reveal that minority teachers have succeeded through flexibility, determination, and ambition, which seems to be true.

\section{References}

Adair, J. K. (2011). Confirming chanclas: What early childhood teacher educators can learn from immigrant preschool teachers. Journal of Early Childhood Teacher Education, 32, 55-71.

Amin, N. (1997). Race and the identity of the nonnative ESL teacher. TESOL Quarterly, 31(3), 580-583.

Amin, N.(2001). Nativism, the native speaker construct, and minority immigrant women teachers of English as a second language. The CATESOL Journal, 13(1), 89-107.

Antonelli, F., Pollock, K., \& Ryan, J. (2009). Teacher diversity in Canada: Leaky pipelines, bottlenecks, and glass ceilings. Canadian Journal of Education, 32(3), 591-617.

Barnett, R. (2008). Critical professionalism in an age of supercomplexity. In B. Cunningham (Ed.), Exploring professionalism (pp. 190-207). London, UK: Institute of Education, University of London.

BBC News. (2015). Pisa tests: Top 40 for maths and reading. Retrieved October 27, 2015 from http:// www.bbc.com/news/business- 26249042

Brindley, S. (2015). A critical investigation of the role of teacher research and its relationship to teacher professionalism, knowledge and identity (Unpublished $\mathrm{PhD}$ dissertation). Institute of Education University of London, London, UK.

Butt, G., MacKenzie, L., \& Manning, R. (2010). Influences on British South Asian women's choice of teaching as a career: "You're either a career person or a family person; teaching kind of fits in the middle." Educational Review, 62(1), 69-83.

Canadian association of university teachers. (2010). The changing academy? CAUT Education Review, 12(1), 1-6. Retrieved from http://www.caut.ca/ docs/education-review/the-changing-academy-aportrait-of-canada-rsquo-s-university-teachers(jan-2010).pdf?sfvrsn=14

Clark, E., \& Paran, A. (2007). The employability of non-native-speaker teachers of EFL: A UK survey. System, 35(4), 407-430.
Cooper, J. M., \& Alvarado, A. (2006). Preparation, recruitment, and retention of teachers (Adobe digital editions version). Retrieved from http://www. unesco.org/iiep/PDF/Edpol5.pdf

Coutts, M. (2013). Toronto school board memo underlines need for male, minority teachers (Adobe digital editions version). Retrieved from https:// ca.news.yahoo.com/blogs/dailybrew/torontoschool-board-memo-underlines-male-minorityteachers-205705777.html

Cruickshank, K. (2004). Towards diversity in teacher education: Teacher preparation of immigrant teachers. European Journal of Teacher Education, 27(2), 125-138.

Demographics of Austria [n.d.]. In Wikipedia. Retrieved December 1, 2015 from https://en.wikipedia.org/ wiki/Demographics_of_Austria\#Ethnic_groups

Egalite, A., \& Kisida, B. (2015). The benefits of minority teachers in the classroom (Adobe digital editions version). Retrieved from http://www. realcleareducation.com/articles/2015/03/06/ minority_teachers_in_the_classroom_1167.html

Eweka, E. U. (2015). School leadership aspirations of black and minority teachers (Unpublished $\mathrm{PhD}$ dissertation). University of Nottingham, Nottingham, UK.

Hargreaves, A. (2000). Four ages of professionalism and professional learning. Teachers and Teaching: History and Practice, 6(2), 151-182.

Hart, S., \& Marshall, J. D. (1992). Question of teacher professionalism. Chicago, IL: The University of Illinois.

Howard, J. (2009). Pride and prejudice...and other barriers to teaching for Asian New Zealanders. Asia Pacific Journal of Education, 29(2), 143-157.

Howard, J. (2010). The value of ethnic diversity in the teaching profession: A New Zealand case study. International Journal of Education, 2(1), 1-22.

Hurtado, S. (2001). Linking diversity and educational purpose: How diversity affects the classroom environment and student development. In G. Orfield (Ed.), Diversity challenged: Evidence on the impact of affirmative action (pp. 187-203). Cambridge, MA: Harvard Education Publishing Group.

Kennedy, A. (2007). Continuing professional development (CPD) policy and the discourse of teacher professionalism in Scotland. Research Papers in Education, 22(1), 95-111. doi:10.1080/02671520601152128

Klein, R. (2015). Recruiting more minority teachers could do wonders for minority students, study says (Adobe digital editions version). Retrieved from http:// www.huffingtonpost.com/2015/03/09/why-recruitminority-teachers_n_6833086.html

Kohli, R. (2009). Critical race reflections: Valuing the experiences of teachers of color in teacher 
education. Race Ethnicity and Education, 12(2), 235251.

Kohli, R. (2014). Unpacking internalized racism: Teachers of color striving for racially just classrooms. Race Ethnicity and Education, 17(3), 367-387.

Luciaka, M., \& Khan-Svik, G. (2008). Intercultural education and intercultural learning in Austria - Critical reflections on theory and practice. Intercultural Education, 19(6), 493-504. Retrieved from https://scholar.google.co.uk/sc holar?bav=on.2,or. \&bvm=bv.110151844, d.amc \&biw $=1245 \&$ bih $=668 \&$ dpr $=1 \& u m=1 \& i e=U T F-$ $8 \& \operatorname{lr} \&$ cites $=302862307912715795$

Macklin, M. (1981). Teaching professionalism to teacher. The Australian Journal of Education, 25(1), 24-36.

Majhanovich, S., \& Rezai-Rashti, G. (2002). Marginalized women: Minority women teachers in twentieth century Ontario. Education and Society, 20(2), 61-72.

Mawhinney, H., \& Xu, F. (1997). Reconstructing the professional identity of foreign-trained teachers in Ontario schools. TESOL Quarterly, 31(3), 632-639.

McIntosh, P. (2015). Extending the knapsack: Using the white privilege analysis to examine conferred advantage and disadvantage. Women \& Therapy, 38(3-4), 232-245.

National education aassociation. (2015). NEA and teacher recruitment: An overview (Adobe digital editions version). Retrieved from http://www.nea. org/home/29031.htm

Nicholson, K. (2014). Professionalism in the workplace (Adobe digital editions version). Retrieved from http://www.slideshare.net/Albany_SS/ professionalism-in-the-workplace-37205201
Norton, B. (1997). Language, identity, and the ownership of English. TESOL Quarterly, 31(3), 409429.

Park, G. (2015). Situating the discourses of privilege and marginalization in the lives of two East Asian women teachers of English. Race Ethnicity and Education, 18(1), 108-133.

Power, S. (2008). The imaginative professional. In B. Cunningham (Ed.), Exploring professionalism (pp. 144-160). London, UK: Institute of Education, University of London.

Richard, M. I., \& May, H. (2011). The minority teacher shortage: Fact or fable? (Adobe digital editions version). Retrieved from http://www.edweek.org/ ew/articles/2011/09/01/kappan_ingersoll.html

Subedi, B. (2008). Contesting racialization: Asian immigrant teachers' critiques and claims of teacher authenticity. Race Ethnicity and Education, 11(1), 57-70.

Tang, C. (1997). The identity of the nonnative ESL teacher on the power and status of nonnative ESL teachers. TESOL Quarterly, 31(3), 577-580.

Thifa, N. (2015). 20 best education system in the world. MBC Times. Retrieved January 4, 2016 from http:// www.mbctimes.com/english/20-best-educationsystems-world

Von Wright, J. (1992). Reflections on reflection. Learning and Instruction, 2, 59-68.

Whitty, G. (2008). Changing modes of teacher professionalism: Traditional, managerial, collaborative and democratic. In B. Cunningham (Ed.), Exploring professionalism (pp. 28-49). London, UK: Institute of Education, University of London.

Whitty, G., Power, S., \& Halpin, D. (1998). Devolution and choice in education: The school, the state and the market. Buckingham, UK: Open University Press. 